\title{
Anhedonia in schizophrenia: The role of subjective experiences
}

\author{
Renata Fortunati $^{\mathrm{a}, \mathrm{b}}$, Paolo Ossola ${ }^{\mathrm{a}, \mathrm{b}}$, Annalisa Camerlengo $^{\mathrm{a}}$, Elena Bettini $^{\mathrm{a}}$, \\ Chiara De Panfilis ${ }^{\mathrm{a}, \mathrm{b}}$, Matteo Tonna ${ }^{\mathrm{b}}$, Carlo Maggini ${ }^{\mathrm{a}}$, Carlo Marchesi ${ }^{\mathrm{a}, \mathrm{b}, *}$ \\ ${ }^{\mathrm{a}}$ Unit of Psychiatry, Department of Neuroscience, University of Parma, University Hospital, Braga Building, via Gramsci, 14, 43126, Parma, Italy \\ ${ }^{\mathrm{b}}$ Mental Health Department, Local Health Agency, University Hospital, Braga Building, via Gramsci, 14, 43126 Parma, Italy
}

\begin{abstract}
Background: High levels of anhedonia have been found in patients with schizophrenia; specifically they report higher levels of social anhedonia rather than physical anhedonia, and further, in the anticipatory rather than consummatory facets of pleasure. Nonetheless, contrasting results emerged regarding the underlying mechanisms of this deficit. Basic Symptoms (BS) disturb subjective experiences present for most of the illness' course; this impacts patients' daily lives leading to a loss of the ability to organize the experience of the self and the world in a fluid and automatic way. Considering the role played by negative emotions in the subjective evaluation of anhedonia, the aim of the study is to clarify the role of BS in the assessment of anhedonia in a sample of patients with schizophrenia $(\mathrm{n}=53)$ compared with healthy controls $(n=46)$.

Methods: Participants completed a self-administered trait questionnaire evaluating social anhedonia (Revised-Social Anhedonia Scale), physical anhedonia (Physical Anhedonia Scale), and the consummatory and anticipatory pleasure experiences (Temporal Experience of Pleasure Scale). BS were evaluated with the Frankfurter Beschwerde-Frageboden (FBF) whereas psychopathology was assessed with the Positive and Negative Syndromes Scale.

Results: Patients scored higher than healthy controls in social, physical and anticipatory anhedonia, but not in consummatory anhedonia and these relationships were mediated by the FBF. Basic Symptoms of Memory, Overstimulation and Lack of Automatism were related to some facets of anhedonia, independently from depressive symptoms.

Conclusions: We hypothesize that a subjective cognitive deficit and a reduced ability in information processing, could prevent patients from retaining a positive experience from past pleasant activities. Therefore the lack of pleasure would be, at least in part, related to an avoidance of potentially stressful new scenarios.

(C) 2015 Elsevier Inc. All rights reserved.
\end{abstract}

\section{Introduction}

The first descriptions of the "failure in the ability to experience pleasure" date back to the XIX century [1-3], but it was the French psychologist Ribot [4] that, in 1896, coined the term anhedonia, in contrast to analgesia, to describe the inability to experience pleasure. The multiple meanings of anhedonia in literature reflect the ambiguous definition of pleasure and the fact that pleasure has always been associated with seeking behaviors [5]. The evaluation of

Financial support: This research received no specific grant from any funding agency, commercial or not-for-profit sectors.

Conflict of interest: None.

* Corresponding author at: Department of Neuroscience, Psychiatry Unit, University of Parma, University Hospital, Braga Building, 43126, Parma, Italy. Tel.: +39 0521 903765; fax: +390521396822.

E-mail address: carlo.marchesi@unipr.it (C. Marchesi). hedonic ability in psychiatry considered both the nature of the stimulus (i.e. physical or social) and the reward-related mechanisms (i.e. wanting or liking) [6-9]. Moreover, pleasure associated with future events could be divided into anticipated (i.e. pleasure expected to be experienced in the future) and anticipatory (i.e. pleasure experienced in the immediate present, imagining future events) [10]. Cognitive mechanism may be involved in anticipated pleasure whereas the anticipatory one relies more on emotional features $[11,12]$.

The first time that the word anhedonia appeared was within a description of Schizophrenia by Pascal [13], although an impairment in the ability to experience pleasure has always been associated with Kraepelin [14] and Bleuler's [15] description of schizophrenia and specifically with the affective flattening. Its role as a distinctive characteristic of schizophrenia was initially hypothesized 
by Myerson [16], but it is only with Rado [17] and Meehl [18] that it acquires a central position in the pathogenesis of the disorder.

Most of the studies observed higher levels of anhedonia in patients with schizophrenia, specifically for social rather than physical experiences $[19,20]$, compared to healthy subjects [21-27]. Furthermore, literature agrees that 'wanting', more than 'liking', is impaired in Schizophrenia [28-31] even in the early phases of the disorder [32]. A limitation of these studies evaluating anhedonia in patients with schizophrenia is the method of its assessment. On the one hand, some of the scales used (i.e. the AnhedoniaAsociality subscale of the Scale for the Assessment of Negative Symptoms, SANS and the Passive/apathetic social withdrawal score at Positive and Negative Syndromes Scale, PANSS) [33,34] chiefly evaluate the behavioral facets of anhedonia, relying on the assumption that the reduction of involvement in pleasant stimuli reflects only an emotional disturbance [35], although anergia, abulia, social anxiety and intentional avoidance of stressful situations could reduce engagement in pleasant situations [36-39].

On the other hand, self-report trait questionnaires (e.g. the Revised-Social Anhedonia Scale, R-SAS; the Physical Anhedonia Scale, PAS; the Temporal Experience of Pleasure Scale, TEPS; and the Snaith Hamilton Pleasure Scale, SHAPS) [40-43] aimed at measuring a more subjective anhedonia, do not capture how some negative emotions affect the patients' score $[44,45]$.

Moreover, in patients with schizophrenia, a discrepancy has been observed between the ability to experience pleasure as assessed by questionnaires (i.e. expressive anhedonia) and that reported in laboratory studies and via experience sampling method (i.e. experiential anhedonia). In fact, levels of positive emotion were similar to those of healthy subjects when providing reports of current feelings, but lower when reporting their noncurrent feelings through representative or retrospective interviews $[12,45,46]$. Remarkably, in the evaluation of current feelings, patients with schizophrenia showed higher levels of negative emotions $[35,47]$ anyway. A peculiar dimension of schizophrenic psychopathology that, by definition, is associated with negative emotions, is the subtle experienced disturbances in drive, affect, thinking, speech, (body) perception, motor action, central vegetative functions and stress tolerance [48]. Patients with schizophrenia experience these disturbing subjective symptoms for most of the illness' course [48].

The first detailed investigations of patient subjective experience in schizophrenia began in the 50s with the studies by Chapman [49] and Huber [50], the latter on the basis of Süllwold's observations on motor disorders [51].

Among these experiences, the most studied are Basic Symptoms: uncharacteristic elementary experiences, confined to the subjective sphere, that are "not behavioural, but experiential in kind" [52] and are the manifestation of disorders in information processing [53] and considered the direct consequence of the neuropathological defect $[49,54]$.
They are present in the pre-, intra- and post-psychotic phases of the disorder.

Schneiderian's first rank symptoms and Negative symptoms hail from these pre-existing disorders along a continuum of psychopathological evolution as an interaction between the personological matrix and coping mechanism [55].

A way in which patients could cope with basic symptoms is the avoidance of new scenarios, which in turn, could evoke them. This is reflected by an impairment in the subject's global functioning [53].

Basic Symptoms may therefore affect a patient's ability to anticipate pleasant events, recalling them and maintaining a hedonic tone. This could result in ambivalent experiences $[56,47]$ that could in part justify the patients' higher scores in questionnaires assessing trait anhedonia.

The aim of the study is to evaluate whether patients with schizophrenia are more anhedonic than healthy controls in self-report trait questionnaires and if this relationship is mediated by Basic Symptoms.

\section{Materials and methods}

\subsection{Sample recruitment and procedure}

The study sample was comprised of 53 patients with schizophrenia recruited among the outpatients service in a Community Mental Health Service and 46 healthy controls (HCs). Exclusion criteria for study participation were: 1) being younger than 18 or older than 65 years old; 2) cognitive impairment (MMSE <25) [57] or language barriers interfering with the capacity to reliably answer diagnostic interviews or questionnaires; 3 ) evidence of substance use disorder; 4) and in the HC group the presence of an axis I or II diagnosis according to DSM-IV-TR diagnostic criteria.

After giving informed consent all patients were interviewed by an expert psychiatrist (R.F.). The study protocol has been approved by the relevant national and institutional committees on human experimentation and according the Helsinki Declaration of 1975, as revised in 2008.

\subsection{Measures}

\subsubsection{Axis I and II pathology}

Current psychiatric disorders were assessed with the Structured Clinical Interview for DSM-IV Axis I disorders Research Version (SCID-I/P-RV) [58].

Psychopathology severity was assessed by means of the Positive and Negative Syndromes Scale (PANSS) [34] and, in the patient group, depressive symptoms were evaluated with the Calgary Depression Scale for Schizophrenia (CDSS) [59]. PANSS consists of three different subscales: positive, negative and general psychopathology. All participants were clinically stable, being defined as no inpatient hospitalization within three months of study participation; in the same way, none of them underwent changes in therapy in the aforementioned time interval. We adopted the CDSS, rather than other instruments to assess depression because it 
showed the best divergent validity (i.e. most accurately differentiated between depressive symptoms from other symptoms of schizophrenia) [60].

In the HC group current depressive symptoms and personality disorders were excluded with the Hamilton Depression Rating Scale (HAM-D score < 8) [61] and with the Structured Interview for DSM-IV Personality (SIDP-IV) [62], respectively. HCs had no history of psychiatric disorder (i.e. medication prescription, psychotherapy or previous hospitalization); moreover they underwent a psychiatric interview that excluded the presence of current and past psychiatric disorders.

\subsubsection{Anhedonia}

All subjects completed the Physical Anhedonia Scale (PAS) [40], Revised Social Anhedonia Scale (R-SAS) [41] and the Snaith-Hamilton Pleasure Scale (SHAPS) [42]. Moreover, they filled out the Temporary Experience of Pleasure Scale (TEPS) [43] that assesses the ability of experiencing pleasure on two subscales, anticipatory and consummatory, with lower scores reflecting higher levels of anhedonia.

\subsubsection{Subjective experiences}

Subjective experiences have been evaluated with the Italian version of the Frankfurt Complaint Questionnaire. Several rating scales for measuring subjective experiences have been published [63] and among these the Frankfurter Beschwerde-Frageboden (FBF) [64], is one of the most frequently used. It covers a great variety of cognitive complaints involving attention, perception, memory, thinking, language, movement and emotions. FBF is a selfadministered 98-item true/false questionnaire that evaluates the presence of Basic Symptoms and has been developed from verbal statements originally made by patients with schizophrenia. The latest version (the third) contains 98 items concerning a wide range of dysfunctions clustered in 10 subscales, these being: Loss of Control (KO), which includes both volitional and cognitive aspects; Simple Perception (WAS), which deals with possible sensorial disturbances; Complex Perception (WAK), which involves polysensorial perception (e.g. synesthesias); Language Disorder (SP), which involves difficulties in both the receptive and expressive facets of language; Thought Disorder (DE), which refers to interference, barrages and other impairment in the flow of thoughts; Memory (GED), which refers to both short-term and more structured longterm memory disturbances; Motility (MO), which evaluates subtle disturbances in motor control or kinesthesias; Lack of Automatization (AU), which explores the loss of some automatic functions and the consequent need to reflect even on some usually natural activities; Anhedonia-Anxiety (AN), which includes several dynamic deficits in drive, affect and emotional resonance; and finally, Overstimulation (REI), which reflects the lower threshold of dealing with stressful events, so that even daily activities could lead to disturbing experiences.

Typical FBF items are as follows: "I'm not able to protect myself sufficiently, everything has too much impact on me" (item 89); "Doing simple daily tasks, I have to think carefully about what comes first and what comes next" (item 38); "I often notice that I cannot remember what I just said or just did" (item 73); "I have many gaps in my memory; many things I knew have disappeared" (item 8).

Subjective Experiences measured with the FBF have shown to constitute a dimension that is independent and distinct from other psychopathological dimensions [65] with unidimensional psychometric properties [66] and high internal consistency $[67,68]$.

\subsubsection{Global functioning}

Global functioning in the whole sample has been assessed with the Personal and Social Performance Scale (PSP) [69], a clinician-administered measure, containing the four main areas: socially useful activities, personal and social relationships, self-care, as well as disturbing and aggressive behaviour.

\subsection{Statistical analyses}

Internal consistency of TEPS has been calculated and a partial confirmatory factor analysis (PCFA) [70] has been performed on the Italian Version of TEPS [71], since to our knowledge it has never been administered to a clinical sample.

We first assessed the normal distribution of variables through the Kolmogorov-Smirnov test. CDSS ( $D=0.193$, $\mathrm{p}=<.001)$, SHAPS $(\mathrm{D}=0.262, \mathrm{p}=<.001)$, TEPS consummatory subscale $(\mathrm{D}=0.174, \mathrm{p}=.001)$, R-SAS $(\mathrm{D}=$ $0.150, \mathrm{p}=<.001)$ and PSP $(\mathrm{D}=0.129, \mathrm{p}=.033)$ were non-normally distributed.

The internal consistency of the TEPS was acceptable in the whole sample (Cronbach's alpha $=.802$ ) and in the two groups (Cronbach's alpha in Healthy Controls $=.806$; Cronbach's alpha in Patient Group $=.784$ ) as much as its subscales (Cronbach's alpha for the Anticipatory subscale $=$ .700; Cronbach's alpha for the Consummatory subscale $=$ .711). A lower alpha has been detected in the patient group for the Anticipatory subscale (Cronbach's alpha $=.646$ ). The results of the partial confirmatory factor analysis (PCFA) confirmed a two factor structure $(\mathrm{KMO}=.705$; Bartlett's test of sphericity: $p<.001$; Good-fit-test: Chisquared $=165.14 ; \quad \mathrm{df}=118 ; \mathrm{p}=.003 ; \quad \mathrm{CFI}=0.90 ;$ RMSEA $=0.06$ ).

The differences among groups were evaluated using Student's $\mathrm{t}$ test for continuous variables with a normal distribution (i.e. age, scores at TEPS anticipatory subscale, PAS) and with Mann-Whitney U for non-normally distributed values (i.e. CDSS, SHAPS, TEPS consummatory subscale, R-SAS, PANSS and PSP) and $\chi^{2}$ for categorical variables (i.e. gender, education, employment and living status).

Similarly Pearson's and Spearman's correlations have been calculated, where appropriate, between the anhedonia scales (PAS, R-SAS, TEPS Anticipatory and Consummatory 
subscales, SHAPS), subjective experiences (FBF) and global functioning (PSP). The correlations between anhedonia scores and general psychopathology (PANSS subscales, CDSS) have been performed in the patient group only.

We next evaluated in the whole sample $(\mathrm{n}=97)$ whether subjective experiences (supposed mediator) mediate the relationship between a diagnosis of Schizophrenia (independent variable) and all the anhedonia scales (outcome variable) using Hayes' bootstrapping procedure for conditional effects (SPSS PROCESS macro, Model \#4) [72]. This procedure makes no assumption about the normality of the data and is more tolerant of a small sample size by utilizing 5000 bootstrap resamples to estimate a $95 \%$ confidence interval for a particular effect. We excluded from the mediation analysis the score at the negative subscale of the PANSS, although significantly different between the two groups, because its scores in the HC were nil (mean $=7.00 ; \mathrm{SD}=.00)$ and its items include to some extent anhedonia. Furthermore, we did not consider 'global functioning' and 'years of education' as covariates as they are almost implied in the diagnosis of Schizophrenia.

Analysis of covariance (ANCOVA with Bonferroni correction), within the patient group, was used to evaluate whether the difference in FBF subscales between anhedonics and non-anhedonics at SHAPS, PAS and R-SAS remained after controlling for the effect of state measures (i.e. CDSS). Since a clear cut-off has not been established for the Anticipatory subscale of TEPS, we performed a linear regression (enter-method) to evaluate which FBF subscale predicted anticipatory anhedonia (TEPS Anticipatory subscale as dependent variable) controlling for depressive symptoms (CDSS entered in the first block).

We carried out all the analysis using SPSS software (version 20.0, IBM SPSS Statistics).

\section{Results}

\subsection{Sample characteristic}

Fifty-three patients with schizophrenia and $46 \mathrm{HCs}$ participated in the study. All the socio-demographic clinical variables of the two groups are shown in Table 1.

In patients with schizophrenia the mean age at onset was $23.56(\mathrm{sd}=5.77)$ and the mean duration of illness was 16.39 $(\mathrm{sd}=9.84)$. They received a diagnosis of Paranoid $(\mathrm{n}=40$; $75.5 \%)$, Disorganized $(\mathrm{n}=5 ; 9.4 \%)$ or Undifferentiated $(\mathrm{n}=8 ; 15.1 \%)$ Schizophrenia. Twenty-five patients were taking an FGA (47.2\%), 26 an SGA (49\%) and two (3.8\%) a combination of an FGA and a SGA.

In the HC group the mean score at HAM-D was 0.57 $(\mathrm{sd}=1.51)$ whereas in the patient group the mean CDSS score was $2.68(\mathrm{sd}=3.16)$.

\subsection{Anhedonia}

The only clinical variable in which patients with schizophrenia did not score differently from HCs was the consummatory subscale of the TEPS, confirming higher anhedonia levels in the patient group and specifically as lower anticipatory pleasure.

TEPS subscales strongly correlated with the other anhedonia scales, global functioning and, within the patient group only, with the negative symptoms at PANSS (Table 2).

Differences between male and female have been found for TEPS consummatory subscale (male $=4.36 \pm .87$; female $=4.82 \pm .87 ; \mathrm{U}=815 ; \mathrm{z}=-2.67 ; \mathrm{p}=.008)$, specifically in the $\mathrm{HC}$ group $($ male $=4.34 \pm .84$; female $=5.06 \pm$ $.62 ; \mathrm{U}=133 ; \mathrm{z}=-2.89 ; \mathrm{p}=.003)$, and for SHAPS $($ male $=1.5 \pm 2.42 ;$ female $=.84 \pm 1.85 ; \quad U=892.5$; $\mathrm{z}=-2.36 ; \mathrm{p}=.018)$. Age correlated significantly with TEPS anticipatory subscale only $(\rho=-.218 ; \mathrm{p}=.031)$.

\subsection{Predictors of anhedonia}

In the whole sample the Mediation Analysis (model \#4) showed a significant indirect effect of Schizophrenia on Anhedonia (i.e. SHAPS, TEPS Anticipatory Subscale, R-SAS and PAS) through subjective experiences as measured at FBF total score with a relatively strong effect across different scales (18\%-27\%) (Fig. 1).

Spearman correlations between the FBF subscales and the four aforementioned anhedonia scales were always significant; nonetheless, the highest values have been found between 'PAS' and 'R-SAS' with 'FBF Overstimulation' (PAS: $\rho=.506 ; p<.001 ;$ R-SAS: $\rho=.595 ; \mathrm{p}<.001$ ) and then between 'SHAPS' and 'TEPS anticipatory subscale' with 'FBF Memory' (SHAPS: $\rho=.461 ; \mathrm{p}<.001$; TEPS Anticipatory Subscale $\rho=-.366 ; \mathrm{p}<.001$ ).

We then divided the patient group into anhedonics and non-anhedonics, according to each scale cut-off (SHAPS: cut off $=3$; R-SAS: cut off $=12 ;$ PAS: cut off $=18$ ) $[40-42,73]$. The mean score at the negative subscale of PANSS in the two groups was not significantly different, confirming previous results [26] and supporting the bimodal distribution of anhedonia in schizophrenia [74].

Differences in FBF subscales have then been computed with the abovementioned dichotomization co-varying for the CDSS (Table 3). The differences between the two groups (anhedonics vs non-anhedonics) remained significant for FBF Memory according to SHAPS cut-off and for FBF Overstimulation, Lack of Automatism and AnhedoniaAnxiety subscales according R-SAS cut-off, suggesting a more stable (trait) effect of these dimensions on Anhedonia scales.

At the linear regression no FBF subscale predicted the TEPS anticipatory score after controlling for CDSS.

\section{Discussion}

In this study, we evaluated the anhedonic features in a sample of patients with schizophrenia matched with a group of healthy controls. 
Table 1

Sociodemographic and clinical characteristic of patients and healthy controls.

\begin{tabular}{|c|c|c|c|c|c|}
\hline & Patients & Healthy Controls & & & $p$ \\
\hline & $\mathrm{n}=53$ & $\mathrm{n}=46$ & & & \\
\hline Sex (M) & $32(60.4 \%)$ & $23(50.0 \%)$ & $x^{2}=1.0$ & & $p=.30$ \\
\hline Age (years) & $40.1 \pm 10.5$ & $38.3 \pm 10.5$ & $\mathrm{t}=.8$ & & $p=.39$ \\
\hline Years of education & $12.3 \pm 3.7$ & $14.1 \pm 2.3$ & $\mathrm{t}=2.8$ & & $p=.006$ \\
\hline Employed & $30(56.6 \%)$ & $39(84.8 \%)$ & $x^{2}=11.4$ & & $p=.003$ \\
\hline Married & $4(7.5 \%)$ & $22(47.8 \%)$ & $x^{2}=20.6$ & & $p=.001$ \\
\hline CDSS & $2.68 \pm 3.16$ & - & & & \\
\hline HAM-D & - & $0.57 \pm 1.51$ & & & \\
\hline TEPS-A & $3.96 \pm 0.81$ & $4.53 \pm 0.71$ & $t=3.65$ & & $p<.001$ \\
\hline TEPS-C & $4.45 \pm 0.96$ & $4.68 \pm 0.78$ & $\mathrm{U}=1032.5$ & $\mathrm{z}=-1.17$ & $\mathrm{p}=.244$ \\
\hline PAS & $19.94 \pm 9.582$ & $12.57 \pm 7.311$ & $t=-4.24$ & & $p<.001$ \\
\hline R-SAS & $13.96 \pm 6.77$ & $8.67 \pm 5.453$ & $\mathrm{U}=636.5$ & $z=-3.99$ & $p<.001$ \\
\hline SHAPS & $1.8 \pm 2.72$ & $0.52 \pm 1.04$ & $\mathrm{U}=834.0$ & $\mathrm{z}=-2.89$ & $\mathrm{p}=.004$ \\
\hline PANSS tot & $78.54 \pm 19$ & $30.8 \pm 1.42$ & $\mathrm{U}=0.00$ & $z=-8.69$ & $p<.001$ \\
\hline PANSS Neg & $21.88 \pm 7.14$ & $7 \pm 0$ & $\mathrm{U}=0.00$ & $\mathrm{z}=-9.02$ & $\mathrm{p}<.001$ \\
\hline PANSS Pos & $16.98 \pm 5.75$ & $7.06 \pm 0.44$ & $\mathrm{U}=4.0$ & $z=-8.96$ & $p<.001$ \\
\hline PANSS Gen & $39.79 \pm 9.69$ & $16.76 \pm 1.35$ & $\mathrm{U}=2.5$ & $\mathrm{z}=-8.67$ & $p<.001$ \\
\hline FBF Total Score & $29.1 \pm 21.7$ & $5.48 \pm 6.31$ & $\mathrm{U}=350.5$ & $\mathrm{z}=-5.95$ & \\
\hline PSP & $44.21 \pm 15.63$ & $80.65 \pm 5.26$ & $\mathrm{U}=19.5$ & $\mathrm{z}=-8.40$ & $\mathrm{p}<.001$ \\
\hline
\end{tabular}

TEPS-A = Anticipatory subscale of the Temporal Experience of Pleasure Scale; TEPS-C = Consummatory subscale of the Temporal Experience of Pleasure Scale; PAS = Physical Anhedonia Scale; R-SAS = Revised-Social Anhedonia Scale; SHAPS = Snaith-Hamilton Pleasure Scale; PANSS tot $=$ total score at Positive and Negative Syndromes Scale; PANSS Neg = Negative subscale at Positive and Negative Syndromes Scale; PANSS Pos = Positive subscale at Positive and Negative Syndromes Scale; PANSS Gen = General Psychopathology at Positive and Negative Syndromes Scale; PSP $=$ Personal and Social Performance Scale.

Patients resulted more anhedonic than healthy controls in physical, social and anticipatory anhedonia, confirming previous results [19-32]. The higher anhedonia levels in the schizophrenic group were mediated by subjective experiences (FBF total score) suggesting a role of Basic

Table 2

Correlations between scales.

\begin{tabular}{lccccc}
\hline & PAS & R-SAS & SHAPS & TEPS-A & TEPS-C \\
\hline PAS & 1 & & & & \\
R-SAS & $.629^{* *}$ & 1 & & & \\
SHAPS & $.620^{* *}$ & $.466^{* *}$ & 1 & & \\
TEPS-A & $-.657^{* *}$, & $-.410^{* *}$ & $-.515^{* *}$ & 1 & \\
TEPS-C & $-.589^{* *}$ & $-.297^{* *}$ & $-.416^{* *}$ & $.552^{* *}$ & 1 \\
PSP & $-.428^{* *}$ & $-.440^{* *}$ & $-.284^{* *}$ & $.417^{* *}$ & .132 \\
FBF & $.484^{* *}$ & $.604^{* *}$ & $.453^{* *}$ & $-.413^{* *}$ & -.189 \\
PANSS-Tot $^{\text {a }}$ & $.504^{* *}$ & $.393^{* *}$ & $.292^{*}$ & $-.353^{*}$ & $-.281^{*}$ \\
PANSS-Neg $^{\text {a }}$ & $.529^{* *}$ & $.380^{* *}$ & $.274^{*}$ & $-.372^{* *}$ & $-.329^{*}$ \\
PANSS-Pos $^{\text {a }}$ & $.318^{*}$ & $294^{*}$ & .141 & -.219 & -.117 \\
PANSS-Gen $^{\text {a }}$ & $.403^{* *}$ & $.299^{*}$ & $.305^{*}$ & $-.312^{*}$ & -.249 \\
CDSS $^{\text {a }}$ & .116 & .241 & .233 & -.175 & -.056 \\
\hline
\end{tabular}

PAS $=$ Physical Anhedonia Scale; R-SAS $=$ Revised-Social Anhedonia Scale; SHAPS $=$ Snaith-Hamilton Pleasure Scale; TEPS-A = Anticipatory subscale of the Temporal Experience of Pleasure Scale; TEPS-C Consummatory subscale of the Temporal Experience of Pleasure Scale; $\mathrm{PSP}=$ Personal and Social Performance Scale. FBF $=$ Frankfurter BeschwerdeFrageboden total score. PANSS tot $=$ total score at Positive and Negative Syndromes Scale; PANSS Neg $=$ Negative subscale at Positive and Negative Syndromes Scale.

a Spearman's correlation calculated in the patient group only.

b Pearson's correlation.

$* \mathrm{p}<.05$.

$* * \mathrm{p}<.001$
Symptoms in the hedonic process. The fact that the relationship between a diagnosis of schizophrenia and anhedonia was explained by Basic Symptoms could mean that, although healthy subjects could manifest a lack of pleasure, only in the Schizophrenic sample was this deficiency partly due to Basic Symptoms.

We found an inverse correlation between age and only one of the pleasure scales (i.e. TEPS-anticipatory). We are

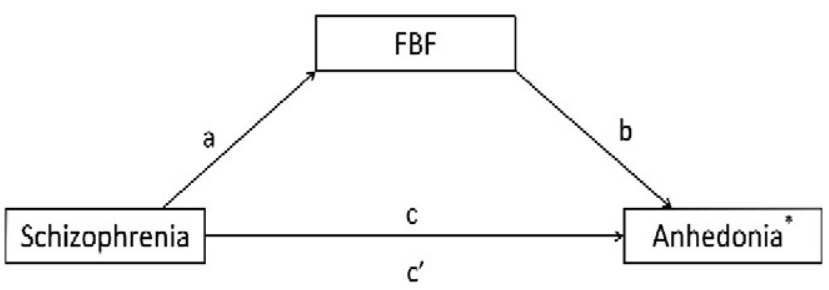

Fig. 1. Mediation of subjective experiences on anticipatory anhedonia in patients with schizophrenia. $\mathrm{c}=$ indirect effect. c' $=$ direct effect. Note: Level of Subjective Experiences, as Basic Symptoms at Frankfurter Beschwerde-Frageboden (FBF) mediating the relationship between a diagnosis of Schizophrenia and all the Scales evaluating Anhedonia (lower scores at TEPS Anticipatory correspond to higher anhedonia levels). Path values correspond to standardized coefficients from the causal steps procedure. *TEPS Anticipatory: $\mathrm{a}=23.62, \mathrm{p}<.001 ; \mathrm{b}=-0.14, \mathrm{p}=.004$; $\mathrm{c}=-3.40$, CI $[-6.12,-1.10] ; \mathrm{c}^{\prime}=-2.29, \mathrm{p}=.20 ; \mathrm{\kappa}^{2}=.18,95 \% \mathrm{BCa} \mathrm{CI}$ $[.06, .29]$. Age as a covariate. *R-SAS: $\mathrm{a}=23.62, \mathrm{p}<.001 ; \mathrm{b}=0.17$, $\mathrm{p}<.001 ; \mathrm{c}=4.00, \mathrm{CI}[2.07,6.32] ; \mathrm{c}^{\prime}=1.36, \mathrm{p}=.34 ; \mathrm{\kappa}^{2}=.27,95 \% \mathrm{BCaCI}$ $[.14, .39] . *$ PAS: $\mathrm{a}=23.62, \mathrm{p}<.001 ; \mathrm{b}=0.21, \mathrm{p}=.001 ; \mathrm{c}=4.87$, CI [2.27, 8.74]; c' $=-2.59, \mathrm{p}=.20 ; \kappa^{2}=.23,95 \%$ BCa CI [.13,.36]. *SHAPS: $\mathrm{a}=$ $23.62, \mathrm{p}<.001 ; \mathrm{b}=0.04, \mathrm{p}<.001 ; \mathrm{c}=1.06$, CI $[0.27,2.06] ; \mathrm{c}^{\prime}=.26, \mathrm{p}=$ $.61 ; \kappa^{2}=.20,95 \% \mathrm{BCa}$ CI $[.06, .34]$. Gender as a covariate. 
Table 3

Significant differences in FBF subscales dividing the patient group according to each scale cut-off and co-varying for CDSS (and gender for SHAPS only).

\begin{tabular}{|c|c|c|c|c|c|}
\hline SHAPS & $\begin{array}{l}\text { Anhedonics } \\
(\mathrm{n}=12)\end{array}$ & $\begin{array}{l}\text { Non-Anhedonics } \\
(\mathrm{n}=41)\end{array}$ & $\mathrm{F}$ & $P$ & Partial $\eta^{2}$ \\
\hline FBF GED & $4.92 \pm 3.1$ & $2.77 \pm 2.6$ & 4.28 & .044 & .082 \\
\hline R-SAS & $\begin{array}{l}\text { Anhedonics } \\
(\mathrm{n}=27)\end{array}$ & $\begin{array}{l}\text { Non-Anhedonics } \\
(\mathrm{n}=26)\end{array}$ & & & \\
\hline FBF REI & $4.03 \pm 2.8$ & $2.04 \pm 2.6$ & 5.76 & .018 & .111 \\
\hline FBF AN & $4.30 \pm 2.3$ & $2.71 \pm 2.2$ & 5.77 & .020 & .107 \\
\hline FBF AU & $4.74 \pm 2.9$ & $2.79 \pm 2.6$ & 5.12 & .028 & .096 \\
\hline
\end{tabular}

SHAPS = Snaith-Hamilton Pleasure Scale; R-SAS = Revised-Social Anhedonia Scale; FBF GED = Memory subscale of FBF; FBF REI = Overstimulation subscale of FBF; FBF AN = Anhedonia-Anxiety subscale of FBF; FBF AU = Lack of Automatism subscale of FBF.

not aware of previous results in literature confirming or disconfirming our finding, therefore we can only suppose that there is an effect of a long lasting illness, since we found a high correlation even between duration of illness and TEPS anticipatory $(\mathrm{r}=-.378 ; \mathrm{p}<.001)$. At present, our small sample size does not allow us to infer a grounded-conclusion regarding this result.

Moreover, we found males being more anhedonic than females and specifically in the consummatory subscale of TEPS, in which patients and control did not differ. This result confirms the gender differences in anhedonia levels found in healthy subjects [75].

Despite the correlation between negative symptoms and scores in the anhedonia scales, we found a similar amount of negative symptoms in the schizophrenic patients, split into anhedonic and non-anhedonic. This finding confirms previous results in the literature that found anhedonia to be independent from negative symptoms [26,74,76-79] and could reflect the ability of these scales (i.e. SHAPS, TEPS, SAS and PAS) to measure a more subjective anhedonia, which does not necessarily lead to behavioral disorders, as measured by the PANSS negative subscale.

The correlation between global functioning and anhedonia confirms previous results in literature [80-82,24].

To our knowledge, this is the first study to observe that individuals with significant levels of anhedonia, not related to depressive symptoms, show specifically higher basic symptoms concerning Memory, Overstimulation, and Lack of Automatism.

No correlation has been found between the anhedonia scores and depressive symptoms; nonetheless, in order to exclude a depressive component we compared Basic Symptoms between Anhedonics and non-anhedonics adjusting for depressive symptoms. Interestingly differences in all the subscales of Basic Symptoms disappear for anticipatory and physical pleasure, but remain a significant effect of some subscales (i.e. Memory, Overstimulation, and Lack of Automatism) on SHAPS and Social anhedonia. According to our results the relationship between Basic Symptoms and physical or anticipatory anhedonia was attributable to a state depressive component (i.e. CDSS). Nonetheless, conclusions based on a state facet should be drawn with precaution, in fact CDSS mean score in the patient group was $2.68 \pm$ 3.16 , well under the suggested threshold $(\operatorname{CDSS}=6)$ for a depressive episode [83] and, despite the cross-sectional design, the sample showed a relative clinical stability $(\geq 3$ months). In addition, the item \#2 of CDSS ("How do you see the future for yourself? Can you see any future?") could overlap at least partially with some items of the TEPS Anticipatory Subscale anhedonia. Whereas SHAPS gauges a more general inability to experience pleasure, it is possible that social anhedonia (R-SAS) describes an anhedonia more characteristic of schizophrenia [84] and related to disturbing subjective experiences.

Basic Symptoms could in fact "contaminate" the experience of positive emotions, affecting the responses in self-report questionnaires. Interestingly in support of this hypothesis, FBF-Overstimulation was significantly related with Social Anhedonia. In fact, according to the Basic Symptoms Model, an excessive stimulation, which overwhelms the reduced patients' abilities in the information processing, increases the emotional arousal turning potentially pleasant social activities into negative and disturbing ones.

Moreover, FBF-Memory includes both short-term disturbances and more structured long-term disturbances (inability to actualize past experiences in a way finalized and adequate to daily situations). We can hypothesize that the short-term deficits would lead patients to renounce those pleasures that request a more preserved working memory (e.g. intellectual pleasures such as reading a book, watching a movie), whereas more structured disturbances in memory could involve a loss of social and professional competence due to the constant need of reconsidering and recollecting what was implicit and acquired. This, along with the finding that social anhedonic patients score higher on the loss of automatism subscale of FBF, is conceptually close to the hyperreflexivity described by Sass and Parnas [85]. Patients, therefore, have to deal with all activities, including those previously experienced as pleasant [86], with considerable effort due to concentration and subsequent stress [87].

This study has some limitations: 1) the small amount of patients in the sample could limit the strength of the clinical results; 2) the validity of self-report questionnaires on anhedonia has been doubted by some authors, because responding to hypothetical items presupposes a certain ability in abstraction/mental representation and a preserved retrieval memory that could be impaired in schizophrenia [46]; 3) recently, the ability of TEPS in dissecting anticipatory and consummatory pleasure has been questioned $[88,89]$ and other factor solutions have been proposed [75]. This being said, further longitudinal studies, with larger sample sizes and the consideration of other measurement techniques (i.e. neuropsychological and reward-related) are needed to overcome the abovementioned limitations. 


\section{Conclusions}

Altogether the results of this study suggest that Basic Symptoms, and their emotional impact, could contribute to the failure in the ability of reporting experienced pleasure observed in patients with schizophrenia. Specifically, Anhedonia measured with SHAPS, and Social Anhedonia, which has been proposed as a trait-like feature in patients with schizophrenia $[90,84]$, were related to Basic Symptoms independently from depressive symptoms. Our results are close to those of Buck and colleagues [91] which, instead evaluated the role of social cognition and metacognition in anhedonia in Schizophrenia, according to which "anhedonia may be linked with greater levels of reality distortion and withdrawal." These authors suggest that metacognition and social cognition are necessary in order to make sense of and regulate social interactions, where an "impairment in the ability to ascribe mental states to others has been suggested to lead to a sense of lack of attunement with others which may then lead to social withdrawal and a dearth of rewarding social experiences" [92]. Interestingly, in the Basic Symptoms model, cognitive deficit of memory, perception and dynamic deficits would lead to the abovementioned "lack of attunement" that in turn may contaminate pleasant experiences.

Uncertainties and contrast arisen regarding the role of anhedonia in Schizophrenia, are mirrored by its ambiguous definition and marginal position within Schizophrenia description: in fact, whereas the term anhedonia occurred only as an associated feature in both DSM-III-R [93] and DSM-IV [94] or DSM-IV-TR [95], it disappeared in DSM-5 [96]. This is partly confirmed by our results: considering the primary nature of BS, anhedonia in patients with schizophrenia could be seen as a secondary phenomenon reflecting an ambivalence that has been central in early descriptions of schizophrenia $[15,18]$.

\section{References}

[1] Haslam J. Observations on melancholy and madness. London: Callow; 1809.

[2] Esquirol E. Des maladies mentales considérées sous les rapports médical, hygiénique et médico-légal, 2 vol. Paris: JB Baillière; 1938.

[3] Griesinger W. Pathologie und Therapie der psychischen Krankheiten. 2nd ed. Stuttgart: Krabbe; 1861.

[4] Ribot J. La Psychologie des sentiments. Paris: Felix Arcan; 1896.

[5] Berrios GE. The anhedonias. In: \& Berrios GE, editor. The history of mental symptoms. Descriptive psychopathology since the nineteenth century. Cambridge: Cambridge University Press; 1996. p. 332-47.

[6] Klein DF. Endogenomorphic depression. A conceptual and terminological revision. Arch Gen Psychiatry 1974;31:447-54.

[7] Ettenberg A. Anhedonia. In: \& Costello C, editor. Symptoms of schizophrenia. New York: Wiley; 1993. p. 121-44.

[8] Berridge KC, Robinson TE. Parsing reward. Trends Neurosci 2003;26:507-13.

[9] Wolf DH. Anhedonia in schizophrenia. Curr Psychiatry Rep 2006;8:322-8.

[10] Loewenstein GF, Weber EU, Hsee CK, Welch N. Risk as feelings. Psychol Bull 2001;127:267-86.
[11] Strauss GP, Wilbur RC, Warren KR, August SM, Gold JM. Anticipatory vs. consummatory pleasure: what is the nature of hedonic deficits in schizophrenia? Psychiatry Res 2011;187:36-41, http://dx. doi.org/10.1016/j.psychres.2011.01.012.

[12] Strauss GP. The emotion paradox of anhedonia in schizophrenia: or is it? Schizophr Bull 2013;39:247-50, http://dx.doi.org/10.1093/schbul/ sbs192.

[13] Pascal C. La démence précoce. Paris: Alcan; 1911.

[14] Kraepelin E. Psychiatrie. 8th ed. Leipzig: Deuticke; 1907.

[15] Bleuler E. Dementia praecox oder Gruppe der Schizophrenien. Leipzig: Deuticke; 1911

[16] Myerson A. Anhedonia: the loss of desire and satisfaction. J Nerv Ment Dis 1922;99:309-27.

[17] Rado S. Psychoanalisis of behaviour: collected papers. New York: Grumeand Stratton; 1956.

[18] Meehl PE. Schizotaxia, schizotypy and schizophrenia. Am Psychol 1962;17:827-38.

[19] Blanchard JJ, Cohen AS. The structure of negative symptoms within schizophrenia: implications for assessment. Schizophr Bull 2006;32: 238-45.

[20] Horan WP, Blanchard JJ, Clark LA, Green MF. Affective traits in schizophrenia and schizotypy. Schizophr Bull 2008;34:856-74, http:/ dx.doi.org/10.1093/schbul/sbn083.

[21] Chapman LJ, Chapman JP, Raulin ML. Scales for physical and social anhedonia. J Abnorm Psychol 1976;85:374-82.

[22] Fenton WS, McGlashan TH. Natural history of schizophrenia subtypes: II. Positive and negative symptoms and long-term course. Arch Gen Psychiatry 1991;48:978-86.

[23] Berenbaum H, Oltmanns TF. Emotional experience and expression in schizophrenia and depression. J Abnorm Psychol 1992;101:37-44.

[24] Blanchard JJ, Mueser KT, Bellack AS. Anhedonia, positive and negative affect, and social functioning in schizophrenia. Schizophr Bull 1998;24:413-24.

[25] Herbener ES, Harrow M. The course of anhedonia during 10 years of schizophrenic illness. J Abnorm Psychol 2002;111:237-48.

[26] Silver H, Shlomo N. Anhedonia and schizophrenia: how much is in the eye of the beholder? Compr Psychiatry 2002;43:65-8.

[27] Schürhoff F, Szöke A, Bellivier F, Turcas C, Villemur M, Tignol J, et al. Anhedonia in schizophrenia: a distinct familial subtype? Schizophr Res 2003;61:59-66.

[28] Gard DE, Kring AM, Gard MG, Horan WP, Green MF. Anhedonia in schizophrenia: distinctions between anticipatory and consummatory pleasure. Schizophr Res 2007;93:253-60.

[29] Favrod J, Ernst F, Giuliani F, Bonsack C. Validation of the Temporal Experience of Pleasure Scale (TEPS) in a French-speaking environment. Encéphale 2009;35:241-8, http://dx.doi.org/10.1016/j.encep.2008.02.013.

[30] Loas G, Monestes JL, Ameller A, Bubrovszky M, Yon V, Wallier J, et al. Traduction et étude de validation de la version française de l'échelle d'expérience temporelle du plaisir: étude chez 125 étudiants et chez 162 sujets présentant un trouble psychiatrique. Ann Med Psychol 2009;167:641-64, http://dx.doi.org/10.1016/j.amp.2009.09.002.

[31] Chan RC, Wang Y, Huang J, Shi Y, Wang Y, Hong X, et al. Anticipatory and consummatory components of the experience of pleasure in schizophrenia: cross-cultural validation and extension. Psychiatry Res 2010;175:181-3, http://dx.doi.org/10.1016/j.psychres.2009.01.020.

[32] Mote J, Minzenberg MJ, Carter CS, Kring AM. Deficits in anticipatory but not consummatory pleasure in people with recent-onset schizophrenia spectrum disorders. Schizophr Res 2014;159:76-9, http:/ dx.doi.org/10.1016/j.schres.2014.07.048.

[33] Andreasen NC. Negative symptoms of schizophrenia: definition and reliability. Arch Gen Psychiatry 1982;39:784-8.

[34] Kay SR, Fiszbein A, Opler LA. The Positive and Negative Syndrome Scale (PANSS) for schizophrenia. Schizophr Bull 1987;13:261-76.

[35] Horan WP, Kring AM, Blanchard JJ. Anhedonia in schizophrenia: a review of assessment strategies. Schizophr Bull 2006;32:259-73.

[36] Keefe RS, Harvey PD, Lenzenweger MF, Davidson M, Apter SH, Schmeidler J, et al. Empirical assessment of the factorial structure of 
clinical symptoms in schizophrenia: negative symptoms. Psychiatry Res 1992;44:153-65.

[37] Sayers SL, Curran PJ, Mueser KT. Factor structure and construct validity of the Scale for the Assessment of Negative Symptoms. Psychol Assess 1996;8:269-80.

[38] Kelley ME, van Kammen DP, Allen DN. Empirical validation of primary negative symptoms: independence from effects of medication and psychosis. Am J Psychiatry 1999;156:406-11.

[39] Kring AM, Barch DM. The motivation and pleasure dimension of negative symptoms: neural substrates and behavioral outputs. Eur Neuropsychopharmacol 2014;24:725-36, http://dx.doi.org/10.1016/ j.euroneuro.2013.06.007.

[40] Chapman LJ, Chapman JP. Physical Anhedonia Scale, unpublished. The revised test. Madison: University of Wisconsin; 1978.

[41] Eckbald ML, Chapman LJ, Chapman JP, Mishlove M. The Revised Social Anhedonia Scale. . Unpublished test. Madison: University of Wisconsin; 1982.

[42] Snaith RP, Hamilton M, Morley S, Humayan A. A scale for the assessment of hedonic tone, the Snaith Hamilton Pleasure Scale. Br J Psychiatry 1995;167:99-103.

[43] Gard DE, Gard MG, Kring AM, John OP. Anticipatory and consummatory components of the experience of pleasure: a scale development study. J Res Pers 2006;40:1086-102.

[44] Trèmeau F, Antonius D, Cacioppo JT, Ziwich R, Butler P, Malaspina $\mathrm{D}$, et al. Anticipated, on-line and remembered positive experience in schizophrenia. Schizophr Res 2010;122:199-205, http://dx.doi.org/ 10.1016/j.schres.2009.10.019.

[45] Cohen AS, Najolia GM, Brown LA, Minor KS. The state-trait disjunction of anhedonia in schizophrenia: potential affective, cognitive and social-based mechanisms. Clin Psychol Rev 2011;31: 440-8, http://dx.doi.org/10.1016/j.cpr.2010.11.001.

[46] Strauss GP, Gold JM. A new perspective on anhedonia in schizophrenia. Am J Psychiatry 2012;169:364-73, http://dx.doi.org/ 10.1176/appi.ajp.2011.11030447.

[47] Cohen AS, Minor KS. Emotional experience in patients with schizophrenia revisited: meta-analysis of laboratory studies. Schizophr Bull 2010;36:143-50, http://dx.doi.org/10.1093/schbul/sbn061.

[48] Huber G. The concept of substrate-close basic symptoms and its significance for the theory and therapy of schizophrenic diseases. Nervenarzt 1983;54:23-32.

[49] Chapman J. The early symptoms of schizophrenia. Br J Psychiatry 1966;112:225-51.

[50] Huber G. Die coenesthetische schizophrenie. Fortschr Neurol Psychiatr 1957;25:491-520.

[51] Süllwold L, Huber G. Schizophrene Basisstörungen. Berlin: SpringerVerlag; 201390.

[52] Huber G, Gross G. The concept of basic symptoms and basic stages and its meaning for schizophrenia and schizoaffective psychoses. In: \& Maggini C, editor. Psicopatologia e clinica della schizophrenia. Pisa: ETS edizioni; 1995.

[53] Gross G, Huber G, Klosterkoetter J, Linz M. Bonner Skala fur die Beurteilung von Basissymptome (Bonn Scale for the Assessment of Basic Symptoms_BSABS). Berlin: Springer; 1987.

[54] Huber G. Reine defektsyndrome und basisstadien endogener Psychosen. Fortschr Neurol Psychiatr 1966;34:409-26.

[55] Klosterkoettrer J. The meaning of basic symptoms for the genesis of the schizophrenic nuclear syndrome. Jpn J Psychiatry Neurol 1992;46:609-30.

[56] Trèmeau F, Antonius D, Cacioppo JT, Ziwich R, Jalbrzikowski M, Saccente E, et al. In support of Bleuler: objective evidence for increased affective ambivalence in schizophrenia based upon evocative testing. Schizophr Res 2009;107:223-31, http://dx.doi.org/10.1016/ j.schres.2008.09.020.

[57] Folstein MF, Folstein SE, McHugh PR. "Mini-mental state": a practical method for grading the cognitive state of patients for the clinician. J Psychiatr Res 1975;12:189-98.

[58] First MB, Spitzer RL, Gibbon M, Williams JBW. Structured clinical interview for DSM-IV axis I disorders (SCID-I/P). Patient ed. New
York: Biometrics Research, New York State Psychiatric Institute; 2002.

[59] Addington D, Addington J, Schissel B. A depression rating scale for schizophrenics. Schizophr Res 1990;3:247-51.

[60] Lako IM, Bruggeman R, Knegtering H, Wiersma D, Schoevers RA, Slooff CJ, et al. A systematic review of instruments to measure depressive symptoms in patients with schizophrenia. J Affect Disord 2012;140:38-47, http://dx.doi.org/10.1016/j.jad.2011.10.014.

[61] Hamilton M. A rating scale for depression. J Neurol Neurosurg Psychiatry 1960;23:56-62.

[62] Pfohl B, Blum N, Zimmerman M. Structured interview for DSM-IV personality. Washington: American Psychiatric Publishing; 1997.

[63] Peralta V, Cuesta MJ. Subjective experience of schizophrenia: a critical review. Compr Psychiatry 1994;35:198-204.

[64] Süllwold L. Frankfurter Beschwerde-Frageboden (FBF). In: Süllwold L, \& Huber G, editors. Schizophrene Basisstorungen. Berlin: Springer; 1986. p. 1-36.

[65] Yon V, Loas G, Brien D. Subjective experiences and the psychopathological dimensions in schizophrenia. Psychiatry Res 2005;137:93-102.

[66] Cuesta MJ, Peralta V, Irigoyen I. Factor analysis of the Frankfurt Complaint Questionnaire in a Spanish sample. Psychopathology 1996;29:46-53

[67] Peralta V, Cuesta MJ. Subjective experiences in psychotic disorders: diagnostic value and clinical correlates. Compr Psychiatry 1998;39:11-5.

[68] Loas G, Yon V, Brien D. Dimensional structure of the Frankfurt complaint questionnaire. Compr Psychiatry 2002;43:397-403.

[69] Morosini PL, Magliano L, Brambilla L, Ugolini S, Pioli R. Development, reliability and accetability of a new version of the DSM-IV Social and Occupational Functioning Assessment Scale (SOFAS) to assess routine social functioning. Acta Psychiatr Scand 2000;101:323-9.

[70] Gignac GE. Partial confirmatory factor analysis: described and illustrated on the NEO-PI-R. J Pers Assess 2009;91:40-7, http:// dx.doi.org/10.1080/00223890802484126.

[71] Stratta P, Pacifico R, Riccardi I, Daneluzzo E, Rossi A. Il piacere anticipatorio e consumatorio: uno studio di validazione della versione italiana della Temporal Experience of Pleasure Scale. Giorn Ital Psicopat 2011;17:322-7.

[72] Hayes AF. Mediation, moderation, and conditional process analysis. New York: Guilford; 2013.

[73] Assouly-Besse F, Dollfus S, Petit M. French translation of the Chapman Social and Physical Anhedonia Questionnaire: validation of the French translation in controls and schizophrenic patients. Encéphale 1995;21:273-84.

[74] Pelizza L, Ferrari A. Anhedonia in schizophrenia and major depression: state or trait? Ann Gen Psychiatry 2009;8:22, http:// dx.doi.org/10.1186/1744-859X-8-22.

[75] Chan RC, Wang Y, Yan C, Zhao Q, McGrath J, Hsi X, et al. A study of trait anhedonia in non-clinical Chinese samples: evidence from the Chapman Scales for Physical and Social Anhedonia. PLoS One 2012;7:e34275, http://dx.doi.org/10.1371/journal.pone.0034275.

[76] Loas G, Boyer P, Legrand A. Anhedonia and negative symptomatology in chronic schizophrenia. Compr Psychiatry 1996;37:5-11.

[77] Loas G, Noisette C, Legrand A, Boyer P. Is anhedonia a specific dimension in chronic schizophrenia? Schizophr Bull 2000;26:495-506.

[78] Loas G, Monestes JL, Ingelaere A, Noisette C, Herbener ES. Stability and relationships between trait or state anhedonia and schizophrenic symptoms in schizophrenia: a 13-year follow-up study. Psychiatry Res 2009;166:132-40, http://dx.doi.org/10.1016/j.psychres.2008.02.010.

[79] Ritsner MS. Anhedonia of patients with schizophrenia and schizoaffective disorder is attributed to personality-related factors rather than to state-dependent clinical symptoms. Clin Schizophr Relat Psychoses 2013;21:1-32.

[80] Rey ER, Bailer J, Bräuer W, Händel M, Laubenstein D, Stein A. Stability trends and longitudinal correlations of negative and positive syndromes within a three-year follow-up of initially hospitalized schizophrenics. Acta Psychiatr Scand 1994;90:405-12. 
[81] Mueser KT, Douglas MS, Bellack AS, Morrison RL. Assessment of enduring deficit and negative symptom subtypes in schizophrenia. Schizophr Bull 1991;17:565-82.

[82] Cohen AS, Dinzeo TJ, Nienow TM, Smith DA, Singer B, Docherty NM. Diminished emotionality and social functioning in schizophrenia. J Nerv Ment Dis 2005;193:796-802.

[83] Addington D, Addington J, Maticka-Tyndale E. Assessing depression in schizophrenia: the Calgary Depression Scale. Br J Psychiatry 1993;163(Suppl 22):39-44.

[84] Blanchard JJ, Horan WP, Brown SA. Diagnostic differences in social anhedonia: a longitudinal study of schizophrenia and major depressive disorder. J Abnorm Psychol 2001;110:363-71.

[85] Sass LA, Parnas J. Schizophrenia, consciousness and the Self. Schizophr Bull 2003;29:427-44.

[86] Herbener ES, Rosen C, Khine T, Sweeney JA. Failure of positive but not negative emotional valence to enhance memory in schizophrenia. J Abnorm Psychol 2007;116:43-55.

[87] Süllwold L. I sintomi-base ed il loro significato per la riabilitazione. In: \& Stanghellini G, editor. Verso la Schizofrenia, la teoria dei sintomi di base. Napoli: Idelson Silvana; 1992. p. 105-14.

[88] Ho PM, Cooper AJ, Hall PJ, Smillie LD. Factor structure and construct validity of the temporal experience of pleasure scales. J Pers Assess 2015;97:200-8, http://dx.doi.org/10.1080/00223891.2014. 940625.

[89] Buck B, Lysaker PH. Consummatory and anticipatory anhedonia in schizophrenia: stability, and associations with emotional distress and social function over six months. Psychiatry Res 2013 Jan 30; 205(1-2):30-5, http://dx.doi.org/10.1016/j.psychres.2012.09.008.

[90] Meehl PE. Toward an integrated theory of schizotaxia, schizotypy, and schizophrenia. J Pers Disord 1990;4:1-99.

[91] Buck KD, McLeod HJ, Gumley A, Dimaggio G, Buck BE, Minor KS, et al. Anhedonia in prolonged schizophrenia spectrum patients with relatively lower vs. higher levels of depression disorders: associations with deficits in social cognition and metacognition. Conscious Cogn 2014;29:68-75, http://dx.doi.org/10.1016/j.concog.2014.07. 005.

[92] Salvatore G, Dimaggio G, Popolo R, Lysaker PH. Deficits in mindreading in stressful contexts and their relationships to social withdrawal in schizophrenia. Bull Menninger Clin 2008;72:191-209, http://dx.doi.org/10.1521/bumc.2008.72.3.191.

[93] American Psychiatric Association. Diagnostic and statistical manual of mental disorders. 3rd ed. rev. Washington: American Psychiatric Association; 1987.

[94] American Psychiatric Association. Diagnostic and statistical manual of mental disorders: DSM-IV. Washington: American Psychiatric Association; 1994.

[95] American Psychiatric Association. Diagnostic and statistical manual of mental disorders: DSM-IV-TR. Washington: American Psychiatric Association; 2000 .

[96] American Psychiatric Association. Diagnostic and statistical manual of mental disorders: DSM 5. Washington: American Psychiatric Association; 2013. 